\title{
Analisa Pengukuran Mandibula Menggunakan Metode Fotogrametri
}

\author{
Safira Puspita ${ }^{1 *}$, I Gusti Bagus Budi Dharma² \\ ${ }^{1,2}$ Departemen Teknik Mesin dan Industri, Universitas Gadjah Mada, Yogyakarta, Indonesia \\ ( ${ }^{*}$ safira.puspita@mail.ugm.ac.id)
}

\begin{abstract}
Abstrak - Pandemik COVID-19 saat ini membuat pasien pascaoperasi mandibula enggan datang ke rumah sakit, sedangkan tenaga medis perlu mengontrol secara langsung kesimetrisan mandibula untuk mengetahui indikator keberhasilan pascaoperasi. Dalam penulisan ini dilakukan analisis pengukuran secara langsung menggunakan caliper dengan 8 titik penting atau 11 jarak titik ukur yang dijadikan sebagai acuan pengukuran baku serta pengukuran tidak langsung menggunakan fotogrametri. Penelitian ini ditujukan untuk membantu tenaga medis mengetahui bagaimana pengukuran secara tidak langsung dilakukan dan mengetahui apakah terdapat perbedaan antara pengukuran langsung dan tidak langsung guna menentukan indikator keberhasilan pascaoperasi. Pengukuran menggunakan fotogrametri dilakukan dengan perangkat lunak Agisoft Metashape Professional 1.7.0 yang merepresentasikan, mengkonversi 2D menjadi 3D. Uji kecukupan data dihasilkan sebanyak 33 responden yang diamati. Kemudian uji Saphiro Wilk untuk pengujian normalitas data menggunakan perangkat lunak IBM SPSS 25. Kemudian pengujian menggunakan paired sample t-test untuk menganalisa jarak titik pengukuran t-it kanan, t-it kiri, it-obi kanan, it-obi kiri, obi-go kanan, obi-go kiri, go-mmb kiri, dan mmbme kiri memiliki nilai $>0.05$ sehingga dapat dinyatakan tidak terdapat perbedaan yang signifikan antara hasil pengukuran langsung dan tidak langsung. Sedangkan jarak titik pengukuran go-mmb kanan, mmb-me kanan dan g-sn memiliki nilai $<0.05$ sehingga dapat dinyatakan memiliki perbedaan yang signifikan antara pengukuran langsung dan tidak langsung.
\end{abstract}

Kata kunci: akurasi; Fotogrametri Mandibula; pengukuran langsung; 3D

\section{PENDAHULUAN}

Mandibula merupakan tulang rahang bawah dan merupakan tulang pada tengkorak yang dapat bergerak dan salah satu tulang yang paling rentan terhadap trauma, sehingga rekonstruksi mandibula sering dilakukan Bezzero dkk (2012). Setiap tahun, ribuan orang menjalani operasi rekonstruksi mandibula menggunakan implan yang berbahan biokompatibel. Fraktur mandibula dapat disebabkan oleh trauma maupun proses patologik. Fraktur traumatik disebabkan oleh kecelakaan kendaraan bermotor sebesar 50,8\%, terjatuh 22,3\%, kekerasan atau perkelahian 18,8\% kecelakaan kerja 2,8\%, kecelakaan berolahraga 3,7\%, dan kecelakaan lainnya $1,6 \%$. Sedangkan fraktur yang disebabkan oleh patologik yaitu kista, tumor tulang, osteogenesis imperfekta, asteomielitis, osteoporosis, atropi atau nekrosis tulang Helmi (2014).

Kondisi pandemik COVID-19 19 saat ini membuat pasien pascaoperasi mandibula enggan melakukan kontrol ke rumah sakit. Sehingga kondisi ini membuat tenaga medis kesulitan dalam melakukan pengukuran langsung terhadap pasien pascaoperasi mandibula. Sehingga diperlukan analisa pengukuran mandibula untuk memudahkan tenaga medis dalam mengontrol kesesuaian kondisi mandibula tanpa melakukan pengukuran langsung. Penelitian yang telah dilakukan sebelumnya menemukan terdapat 8 titik penting atau 11 jarak titik kanan dan kiri dalam melakukan pengukuran mandibula diantaranya mid mandibular border, menton, tragion, glabella, subnasale, otobasion inferius, dan intertragion serta t-it, it-obi, obi-go, go-mmb, mmb-me, kanan kiri dan g-sn Kurniawan (2020). 8 titik penting atau 11 jarak titik tersebut dinilai dapat merepresentasikan kondisi mandibula manusia dengan tepat.

Tujuan dari penelitian ini yaitu bagaimana melakukan pengukuran terhadap 8 titik penting atau 11 jarak titik yang diteliti dalam penelitian sebelumnya dan mengetahui perbedaan antara pengukuran langsung dengan pengukuran tidak langsung yang dapat membantu tenaga medis dalam menganalisa hasil pengukuran tersebut sebagai indikator keberhasilan pascaoperasi yaitu menganalisa kesimetrisan mandibula manusia. Manfaat penelitian ini yaitu dapat digunakan sebagai kontrol dalam menentukan indikator keberhasilan dalam rekonstruksi mandibula pascaoperasi. Berdasarkan pembahasan dari beberapa literatur, diperoleh bahwa pengukuran tidak langsung banyak diteliti pada objek bangunan, peninggalan sejarah, tengkorak, wajah, dan mekanisme buka tutup mandibula. Sehingga peluang penelitian yang direkomendasikan pada penelitian ini adalah menganalisa bagaimana melakukan pengukuran secara tidak langsung dan apakah terdapat perbedaan 
antara pengukuran secara langsung dengan pengukuran tidak langsung menggunakan metode fotogrametri pada 8 titik penting atau 11 jarak titik.

\section{STUDI LITERATUR}

\subsection{Pengertian Mandibula}

Mandibula merupakan suatu tulang yang dapat bergerak dan berada pada tubuh bagian atas. Menurut penelitian yang dilakukan oleh Kurniawan, (2020) titik pengukuran yang diamati terdiri atas 8 titik diantaranya yaitu:

1. Menton (me') adalah titik median paling inferior pada dagu yang ditentukan dengan inspeksi secara langsung (gambar 1).

2. Tragion $\left(\mathrm{t}^{\prime}\right)$ yang adalah titik pada takik diatas tragus pada telinga (proyeksi kartilago terletak di anterior external auditory canal), dimana bagian tepi atas kartilago menghilang ke kulit wajah yang ditentukan dengan inspeksi secara langsung (gambar 1).

3. Glabella $\left(\mathrm{g}^{\prime}\right)$ adalah titik paling anterior pada midline di dahi, pada area bubungan supersiliaris yang ditentukan dengan inspeksi secara langsung (gambar 1).

4. Subnasale ( $\left.\mathrm{sn}^{\prime}\right)$ adalah titik yang berada pada pertemuan batas bawah septum nasal dan philtrum yang, ditentukan dengan inspeksi secara langsung (gambar 1).

5. Otobasion inferius (obi') adalah titik paling inferior dari perlekatan cuping telinga dan pipi yang ditentukan dengan inspeksi secara langsung (gambar 1).

6. Intertragion (it') adalah titik puncak dari alur antara tragus dan antitragus yang ditentukan dengan inspeksi secara langsung (gambar 1).

7. Gonion (go') adalah titik di sudut rahang bawah yang merupakan pertemuan antara dua garis, yaitu garis yang menghubungkan titik menton dan titik paling inferior corpus mandibula dengan garis yang menghubungkan titik tragion dengan titik paling posterior ramus ascending mandibula (gambar 1). Penentuan titik gonion dilakukan dengan direct facial method dimana palpasi dilakukan untuk menentukan titik paling inferior corpus mandibula dan titik paling posterior ramus ascending mandibula, sedangkan titik menton dan tragion ditentukan dengan inspeksi secara langsung. Titik menton dihubungkan dengan titik paling inferior corpus mandibula dan titik tragion dihubungkan dengan titik paling posterior ramus ascending mandibula sehingga diperoleh titik pertemuan antara dua garis yang merupakan titik gonion (gambar 1).

8. Mid-mandibular border ( $\mathrm{mmb}^{\prime}$ ) adalah titik yang berada pada batas bawah corpus mandibula, pertengahan titik menton dan titik gonion (gambar 1). Penentuan titik mid-mandibular border dilakukan dengan cara menghubungkan titik menton dan titik gonion kemudian menghitung jaraknya menggunakan jangka sorong. Titik tengah dari jarak yang diperoleh merupakan titik mid-mandibular border (gambar 1).
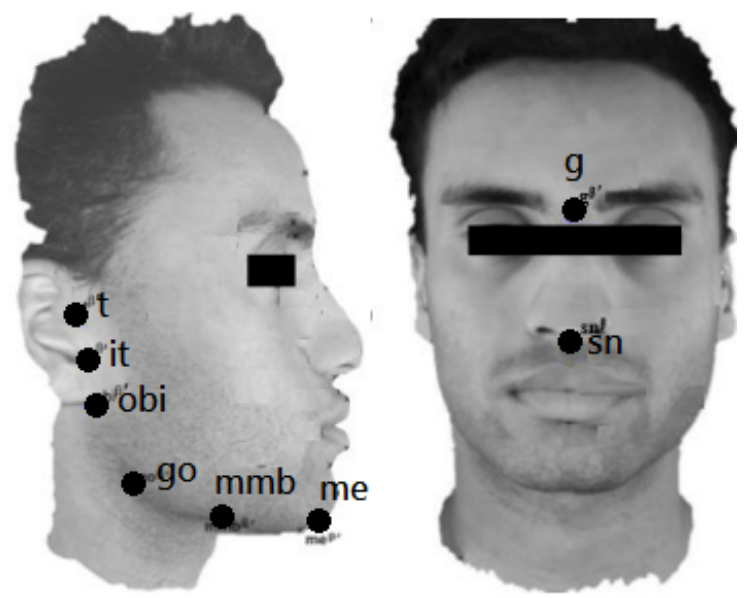

$\begin{array}{ll}\text { Keterangan: } & \\ \mathrm{t} & : \text { tragion } \\ \mathrm{it} & : \text { intertragion } \\ \text { obi } & : \text { otobasion inferius } \\ \text { go } & : \text { gonion } \\ \mathrm{mmb} & : \text { mid-mandibular border } \\ \mathrm{me} & : \text { menton } \\ \mathrm{g} & : \text { glabella } \\ \mathrm{sn} & : \text { subnasale }\end{array}$

Sumber: (Kurniawan, 2020)

Gambar 1. Titik Acuan Sefalometri 


\subsection{Posisi Penelitian}

Berdasarkan studi literatur yang telah dilakukan, diperoleh ide utama dalam penelitian ini. Ide tersebut didapatkan berdasarkan kondisi pandemik yang terjadi saat ini, dimana pengukuran langsung sulit dilakukan akibat terjadinya lonjakan kasus penularan COVID-19. Sehingga interaksi antara manusia sulit dilakukan termasuk pengukuran langsung yang dilakukan oleh tenaga medis terhadap pasien pascaoperasi tulang pipih berbentuk U atau mandibula. Menurut (Jones \& Church, 2020) pengumpulan data menggunakan fotogrametri dilakukan dengan mudah, murah dan tidak menyentuh atau harus mendekati objek secara fisik.

Penelitian-penelitian sebelumnya peneliti hanya melakukan pemodelan terhadap objek pada benda, bangunan dan bagian tubuh. Penelitian pada objek benda diantaranya batu, koin dan arca. Sementara penelitian mengenai bangunan dilakukan, diantaranya pada candi dan peninggalan sejarah. Penelitian mengenai bagian tubuh dilakukan, diantaranya meneliti tentang objek mandibula yaitu dengan parameter pengamatan pada pembukaan dan penutupan rahang manusia, wajah, kaki dan tengkorak. Namun, penelitian mengenai pemodelan pada tulang pipih berbentuk $U$ atau mandibula untuk membuat dan menganalisis perbandingan pengukuran mandibula menggunakan metode fotogrametri terhadap 8 titik penting masih belum dilakukan. Sehingga saat ini masih belum ditemukan penelitian mengenai analisis perbandingan pengukuran mandibula menggunakan metode fotogrametri. Mengingat masih sedikitnya penelitian yang membandingkan antara pengukuran langsung dan tidak langsung untuk menganalisa pengukuran mandibula. Oleh karenanya dengan mempertimbangkan hal tersebut maka pada penelitian ini, peneliti ingin mengamati objek dengan memodelkan tulang pipih berbentuk $U$ atau mandibula dengan menganalisa bagaimana pengukuran mandibula menggunakan metode fotogrametri dalam mengontrol kesimetrisan mandibula pascaoperasi. Selain itu, peneliti ingin mengetahui apakah terdapat perbedaan antara pengukuran langsung dengan pengukuran tidak langsung menggunakan metode fotogrametri dalam mengontrol kesimetrisan mandibula pascaoperasi. Hal ini diakibatkan karena pada kondisi pandemik saat ini pengukuran langsung sulit dilakukan dan beresiko meningkatkan penyebaran COVID-19.

Literatur yang dicari didapatkan dari jurnal Science Direct dan beberapa didapat dari penulisan tugas akhir tahun 2016-2021. Penelitian yang dicari menggunakan kata kunci fotogrametri, mandibula dan fotogrametri mandibula.

Tabel 1

Peluang Penelitian

\begin{tabular}{|c|c|c|c|c|c|c|}
\hline \multirow{3}{*}{ Tujuan } & \multicolumn{6}{|c|}{ Objek } \\
\hline & \multirow{2}{*}{ Benda } & \multirow{2}{*}{ Bangunan } & \multicolumn{4}{|c|}{ Bagian Tubuh } \\
\hline & & & Mandibula & Wajah & Kaki & Tengkorak \\
\hline $\begin{array}{l}\text { Memperkirakan } \\
\text { model dan volume }\end{array}$ & $\begin{array}{c}\text { (Jones \& } \\
\text { Church, 2020) } \\
\text { (Kingsland, } \\
\text { 2020) (Fonseca } \\
\text { Moro \& Pérez } \\
\text { Pavón, } \\
\text { 2021)(Ozturk } \\
\text { \& Rashidzade, } \\
\text { 2020) }\end{array}$ & $\begin{array}{c}\text { (Fioretti } \\
\text { dkk., 2020) }\end{array}$ & & & $\begin{array}{l}\text { (Ardighasakti, } \\
\text { 2020) }\end{array}$ & \\
\hline $\begin{array}{c}\text { Membuat SOP dengan } \\
\text { membandingkan } \\
\text { akurasi antara metode } \\
\text { konvensional dengan } \\
\text { fotogrametri }\end{array}$ & $\begin{array}{l}\text { (Revilla-León } \\
\text { dkk., 2021) }\end{array}$ & & $\begin{array}{l}\text { Penelitian } \\
\text { Ini }\end{array}$ & $\begin{array}{c}\text { (Manosudprasit } \\
\text { dkk., 2017) }\end{array}$ & & \\
\hline $\begin{array}{c}\text { Mengevaluasi } \\
\text { Keandalan dan } \\
\text { akurasi pengukuran }\end{array}$ & $\begin{array}{l}\text { (Larsen dkk., } \\
\text { 2021)(Ortiz- } \\
\text { Sanz dkk., } \\
\text { 2021) (Stuani } \\
\text { dkk., 2019) } \\
\end{array}$ & & $\begin{array}{c}\text { (Andrade } \\
\text { dkk., 2019) }\end{array}$ & $\begin{array}{l}\text { (Ananingtyas } \\
\text { dkk., 2016) }\end{array}$ & & $\begin{array}{l}\text { (Barbero- } \\
\text { García } \\
\text { dkk., 2017) }\end{array}$ \\
\hline $\begin{array}{c}\text { Menganalisis } \\
\text { kemampuan kamera }\end{array}$ & & $\begin{array}{l}\text { (Kalyubi, } \\
\text { 2018) }\end{array}$ & & & & \\
\hline
\end{tabular}




\section{METODOLOGI}

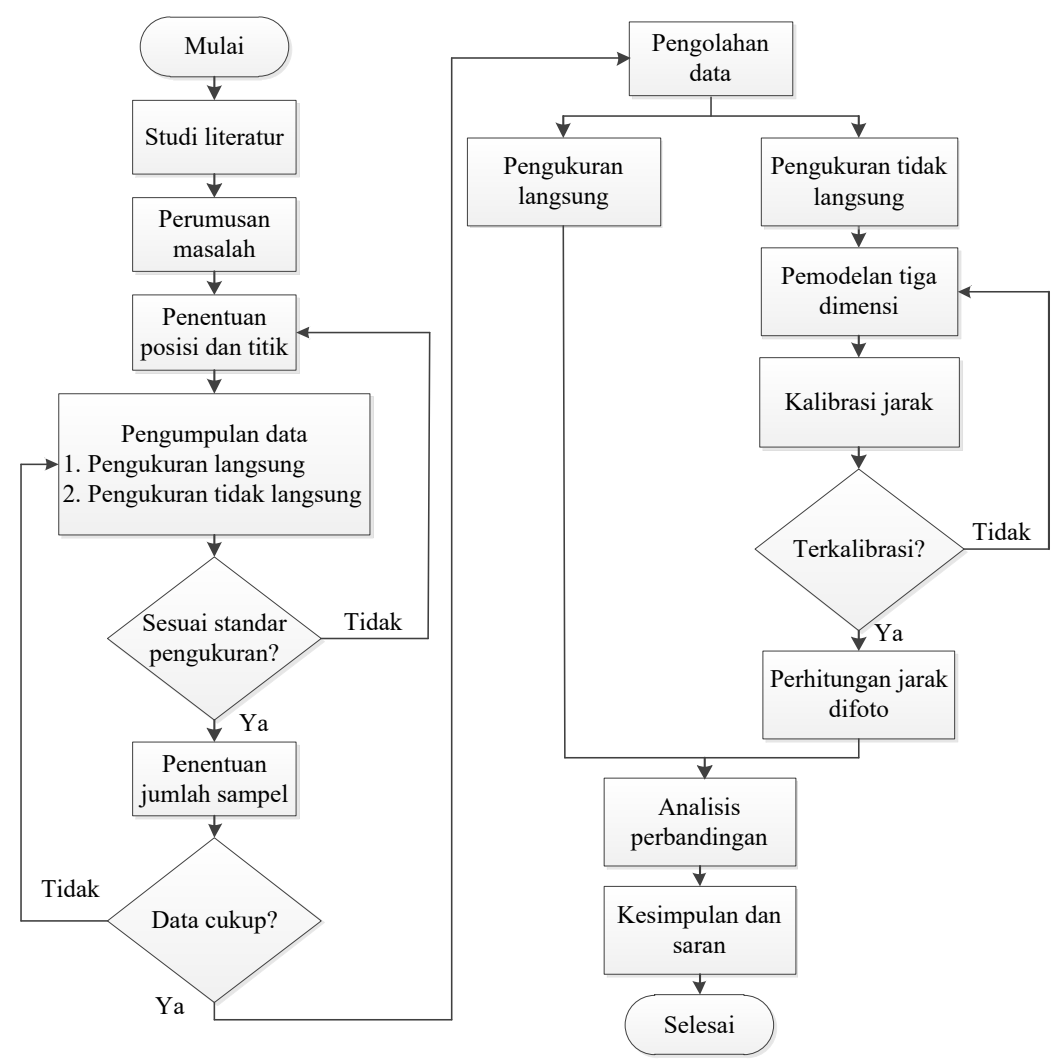

Gambar 2. Alur Penelitian

Berdasarkan studi literatur yang dilakukan, maka didapatkan tujuan, perumusan masalah dalam penelitian ini. Dalam penelitian ini penentuan posisi dalam pengambilan gambar dilakukan dalam jarak dekat $\pm 30 \mathrm{~cm}$ atau foto close-up sebanyak 9 kali. Posisi pengambilan gambar dilakukan dengan total jangkauan sudut sebesar $180^{\circ}$ dan tiap $20^{\circ}$ mengambil gambar dengan posisi yang berbeda dimulai pada tampak samping kanan dan berakhir pada tampak samping kiri. Hal ini dilakukan untuk mendapatkan sudut pandang keseluruhan. Sedangkan penentuan titik didasarkan pada penelitian yang dilakukan sebelumnya. Terdapat 8 titik penting atau 11 jarak titik kanan kiri dalam melakukan pengukuran mandibula diantaranya mid mandibular border, menton, tragion, glabella, subnasale, otobasion inferius, dan intertragion serta t-it, it-obi, obi-go, go-mmb, mmb-me kanan kiri dan g-sn. Dalam proses pengambilan gambar responden diminta untuk tetap fokus pada satu titik dan tidak berbicara atau bergerak. Kemudian dilakukan perhitungan jarak untuk mengetahui ukuran dari titik tersebut.

Pengumpulan data terbagi atas dua metode yaitu pada pengumpulan data secara langsung menggunakan alat berupa caliper dan pengukuran data secara tidak langsung menggunakan metode fotogrametri. Pengukuran tidak langsung menggunakan metode fotogrametri dilakukan dengan menyiapkan aplikasi ruler untuk menghitung jarak yang terbaca dalam gambar 3D, penggaris untuk kalibrasi jarak pada aplikasi, dan stiker untuk menandai 8 titik pengukuran. Selanjutnya penentuan jumlah sampel dilakukan dengan melakukan uji kecukupan data dan didapatkan 33 data.

Tahap selanjutnya pengolahan data yang dilakukan dengan uji normalitas menggunakan metode saphiro wilk dan uji t-test untuk mengetahui signifikasi dari hasil pengukuran langsung dan tidak langsung menggunakan perangkat lunak IBM SPSS 25. Pengolahan data pada pengukuran tidak langsung terlebih dahulu dilakukan memodelkan gambar 3D dan dilanjutkan dengan kalibrasi jarak untuk mengetahui jarak pada gambar 3D tersebut. pada tahap ini akan dilakukan analisis perbandingan dengan membandingkan pengukuran langsung dengan pengukuran tidak langsung menggunakan perangkat lunak Agisoft Metashape Professional Versi 1.7.0. Selanjutnya tahap terakhir berupa pemaparan kesimpulan dan saran berdasarkan hasil pengolahan data. 
Hipotesis dalam penelitian ini yaitu tidak terdapat perbedaan antara pengukuran langsung dengan pengukuran tidak langsung menggunakan metode fotogrametri terhadap 8 titik penting atau 11 jarak titik pengukuran t-it kanan dan kiri, it-obi kanan dan kiri, obi-go kanan dan kiri, go-mmb kanan dan kiri, mmb-me kanan dan kiri serta g-sn.

\section{HASIL DAN DISKUSI}

\section{A. Pengumpulan Data}

Proses pengumpulan data dilakukan terhadap objek laki-laki dan perempuan dengan rentang usia 15-50 tahun. Pengumpulan data dilakukan dengan melakukan pengukuran langsung dan pengukuran tidak langsung. Pengukuran langsung dan tidak langsung dilakukan dengan mengukur 8 titik atau 11 jarak titik diantaranya tragion, intertragion, otobasion inferius, gonion, mid-mandibular border, menton, glabella dan subnasale.

Tabel 2

Uji Kecukupan Data

\begin{tabular}{|c|c|c|c|}
\hline Titik Pengukuran & $\mathrm{N}$ & $\mathrm{N}^{\prime}$ & Kesimpulan \\
\hline t-it kanan & 33 & 29.4711 & cukup \\
\hline t-it kiri & 33 & 29.6625 & cukup \\
\hline it-obi kanan & 33 & 32.0815 & cukup \\
\hline it-obi kiri & 33 & 32.5442 & cukup \\
\hline obi-go kanan & 33 & 32.6255 & cukup \\
\hline obi-go kiri & 33 & 31.9133 & cukup \\
\hline go-mmb kanan & 33 & 12.2722 & cukup \\
\hline go-mmb kiri & 33 & 12.4075 & cukup \\
\hline mmb-me kanan & 33 & 12.2722 & cukup \\
\hline mmb-me kiri & 33 & 12.4075 & cukup \\
\hline g-sn & 33 & 9.5608 & cukup \\
\hline
\end{tabular}

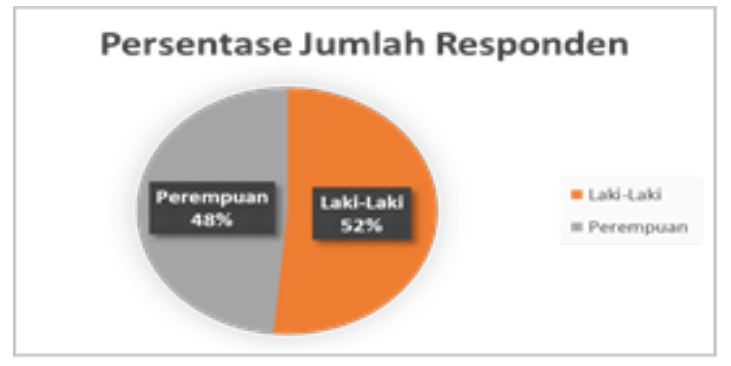

Gambar 3. Persentase Jumlah Responden

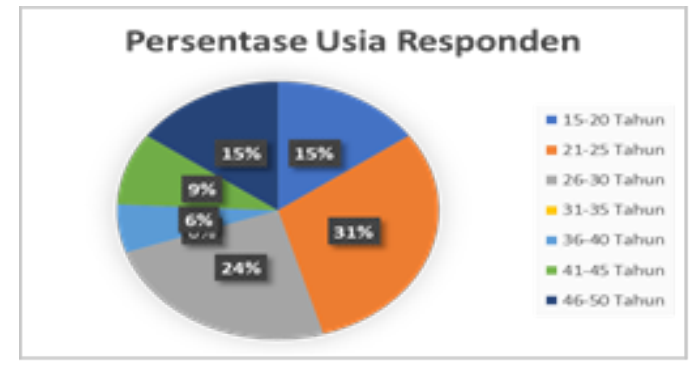

Gambar 4. Persentase Usia Responden

\section{B. Uji Normalitas Data}

Pengujian normalitas data menggunakan metode Saphiro Wilk merupakan uji normalitas yang efektif dan valid untuk sampel data $9 \leq \mathrm{N} \leq 50$ dengan tingkat signifikansi $5 \%$. 
Tabel 3

Uji Normalitas Data

\begin{tabular}{|c|c|c|c|c|c|c|c|}
\hline $\begin{array}{c}\text { Titik Pengukuran } \\
\text { Langsung }\end{array}$ & $\mathrm{N}$ & Sig. & Kesimpulan & $\begin{array}{c}\text { Titik Pengukuran } \\
\text { Tidak Langsung }\end{array}$ & $\mathrm{N}$ & Sig. & Kesimpulan \\
\hline t-it kanan & 33 & 0.061 & Normal & t-it kanan & 33 & 0.125 & Normal \\
\hline t-it kiri & 33 & 0.062 & Normal & t-it kiri & 33 & 0.124 & Normal \\
\hline it-obi kanan & 33 & 0.678 & Normal & it-obi kanan & 33 & 0.561 & Normal \\
\hline it-obi kiri & 33 & 0.586 & Normal & it-obi kiri & 33 & 0.591 & Normal \\
\hline obi-go kanan & 33 & 0.438 & Normal & obi-go kanan & 33 & 0.415 & Normal \\
\hline obi-go kiri & 33 & 0.096 & Normal & obi-go kiri & 33 & 0.114 & Normal \\
\hline go-mmb kanan & 33 & 0.096 & Normal & go-mmb kanan & 33 & 0.114 & Normal \\
\hline go-mmb kiri & 33 & 0.106 & Normal & go-mmb kiri & 33 & 0.123 & Normal \\
\hline mmb-me kanan & 33 & 0.145 & Normal & mmb-me kanan & 33 & 0.119 & Normal \\
\hline mmb-me kiri & 33 & 0.107 & Normal & mmb-me kiri & 33 & 0.124 & Normal \\
\hline g-sn & 33 & 0.076 & Normal & g-sn & 33 & 0.079 & Normal \\
\hline
\end{tabular}

\section{Pemodelan Gambar 3D}

Pemodelan gambar 3D dilakukan untuk merepresentasikan wajah secara keseluruhan dan sesuai dengankondisi sebenarnya. Tujuan pemodelan gambar 3D yang dilakukan yaitu untuk mempermudah proses pengukuran yang dilakukan secara tidak langsung.

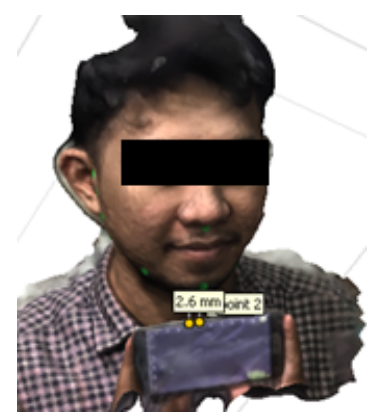

Gambar 5. Pemodelan Gambar 3D

\section{Uji T-Test Berpasangan}

Uji T-Test berpasangan merupakan uji beda dua sampel berpasangan, dimana sampel berpasangan merupakan subjek yang sama namun mengalami perlakuan yang berbeda. Pengujian paired samples t-test dapat dilakukan apabila data tersebut sudah memenuhi syarat yaitu data berdistribusi normal. 
Tabel 4

Hasil Uji T-Test Berpasangan

\begin{tabular}{|c|c|c|}
\hline Pengukuran Langsung dan Tidak Langsung & Sig (2-tailed) & Kesimpulan \\
\hline t-it kanan & 0.066 & Tidak terdapat perbedaan yang signifikan \\
\hline t-it kiri & 0.122 & Tidak terdapat perbedaan yang signifikan \\
\hline it-obi kanan & 0.237 & Tidak terdapat perbedaan yang signifikan \\
\hline it-obi kiri & 0.084 & Tidak terdapat perbedaan yang signifikan \\
\hline obi-go kanan & 0.963 & Tidak terdapat perbedaan yang signifikan \\
\hline obi-go kiri & 0.103 & Tidak terdapat perbedaan yang signifikan \\
\hline go-mmb kanan & 0.017 & Terdapat perbedaan yang signifikan \\
\hline go-mmb kiri & 0.143 & Tidak terdapat perbedaan yang signifikan \\
\hline mmb-me kanan & 0.022 & Terdapat perbedaan yang signifikan \\
\hline mmb-me kiri & 0.142 & Tidak terdapat perbedaan yang signifikan \\
\hline g-sn & 0.000 & Terdapat perbedaan yang signifikan \\
\hline
\end{tabular}

\section{KESIMPULAN}

Berdasarkan hasil pembahasan, maka pengukuran tidak langsung menggunakan metode fotogrametri dilakukan dengan menyiapkan aplikasi ruler untuk menghitung jarak, penggaris untuk kalibrasi jarak pada aplikasi, stiker untuk menandai titik pengukuran yaitu pada titik tragion, intertragion, otobasion inferius, gonion, mid mandibular border, menton, glabella dan subnasale. Setelah itu menentukan jarak antar titik tersebut dengan menggunakan caliper. Responden fokus pada satu titik dan tidak berbicara atau bergerak selama pengambilan foto. Pengambilan foto dilakukan dengan jarak $\pm 30 \mathrm{~cm}$ atau foto secara close-up sebanyak 9 kali dengan sudut keseluruhan $180^{\circ}$. Dimulai dari tampak samping kanan dan berakhir pada tampak samping kiri. Sementara didapatkan tingkat perbedaan yang tidak signifikan pada t-it kanan, i-it kiri, it-obi kanan, it-obi kiri, obi-go kanan, obi-go kiri, go-mmb kiri dan mmb-me kiri dengan nilai uji t-test berpasangan yaitu $>0.05$ dan titik pengukuran go-mmb kanan, mmb-me kanan dan g-sn memiliki nilai pada pengujian t-test berpasangan $<0.05$. Sehingga jarak titik t-it kanan, i-it kiri, it-obi kanan, it-obi kiri, obi-go kanan, obi-go kiri, go-mmb kiri dan mmb-me kiri dapat dijadikan acuan dalam membantu tenaga medis dalam melakukan pengukuran mandibula serta membantu dalam menentukan indikator keberhasilan pascaoperasi dengan pengukuran menggunakan fotogrametri

Hal yang dapat dijadikan penelitian selanjutnya adalah bagaimana menentukan titik pengukuran secara akurat pada ke 8 titik yang menjadi pengamatan yaitu mid mandibular border, menton, tragion, glabella, subnasale, otobasion inferius, dan intertragion. Selain itu, diperlukan penelitian lanjutan terkait perbandingan akurasi dari masing-masing perangkat lunak untuk gambar hasil fotogrametri.

\section{DAFTAR PUSTAKA}

Ananingtyas, F., Prasetyo, Y., \& Suprayogi, A. (2016). Aplikasi fotogrammetri jarak dekat untuk pemodelan 3d wajah manusia (Vol. 5, Issue 2).

Andrade, R. M., Guimarães, L. R., Ribeiro, A. P., Pasqual Marques, A., Crivello, O., Gonçalves de Carvalho, B. K., \& Amado João, S. M. (2019). Reliability in mandibular movement evaluation using photogrammetry in patients with temporomandibular disorders. Journal of Manipulative and Physiological Therapeutics, 42(4), 267-275.

Ardighasakti, C. D. (2020). Aplikasi teknologi digital fotogrametri untuk mempermudah proses reverse engineering kaki.[Unpublished Bachelor Theses]. Universitas Atmajaya Yogyakarta.

Barbero-García, I., Lerma, J. L., Marqués-Mateu, Á., \& Miranda, P. (2017). Low-Cost Smartphone-Based Photogrammetry for the Analysis of Cranial Deformation in Infants. World Neurosurgery, 102, 545-554.

Bezerro TP, Silva Junior FI, Scarparo HC, Costa FWG, and Studart-Soares EC. (2012). Do erupted third 
molars weaken the mandibular angle after trauma to the chin region A 3D finite element study. International Journal of Oral\&Maxillofacial Surgery. 42(4): $474-480$.

Kurniawan, Iwan. (2020). Evaluasi penggunaan plate positioning guide (PPG) terhadap kesimetrisan sepertiga wajah bawah pasca Tindakan hemimandibulektomi di RSUP DR. Sardjito Yogyakarta (kajian geometris tahun 2014-2019). [Unpublish Bachelor Theses]. Universitas Gadjah Mada.

Fioretti, G., Campobasso, C., \& Capotorto, S. (2020). Digital photogrammetry as tool for mensiochronological analysis: The case of st. Maria Veterana archaeological site (Triggiano, Italy). Digital Applications in Archaeology and Cultural Heritage, 19.

Fonseca Moro, L. A., \& Pérez Pavón, J. L. (2021). Study for the documentation of an engraving of Siega Verde (Salamanca, Spain) by low-cost photogrammetry with a mobile phone. Digital Applications in Archaeology and Cultural Heritage, 21.

Jones, C. A., \& Church, E. (2020). Photogrammetry is for everyone: Structure-from-motion software user experiences in archaeology. Journal of Archaeological Science: Reports, 30.

Helmi, Z. (2014). Buku ajar gangguan muskulokeletal. Jakarta: Salemba Medika.

Kalyubi, I. (2018). Analisis potensi kamera smartphone untuk pemodelan 3 dimensi dengan fotogrametri jarak dekat. [Unpublished Bachelor Theses]. Institut Teknologi Sepuluh Nopember

Kingsland, K. (2020). Comparative analysis of digital photogrammetry software for cultural heritage. Digital Applications in Archaeology and Cultural Heritage, 18.

Larsen, H., Budka, M., \& Bennett, M. R. (2021). Technological innovation in the recovery and analysis of 3D forensic footwear evidence: Structure from motion (SfM) photogrammetry. Science and Justice, 61(4), 356-368.

Manosudprasit, A., Haghi, A., Allareddy, V., \& Masoud, M. I. (2017). Diagnosis and treatment planning of orthodontic patients with 3-dimensional dentofacial records. American Journal of Orthodontics and Dentofacial Orthopedics, 151(6), 1083-1091.

Ortiz-Sanz, J., Gil-Docampo, M., Rego-Sanmartín, T., Arza-García, M., \& Tucci, G. (2021). A PBeL for training non-experts in mobile-based photogrammetry and accurate 3-D recording of small-size/noncomplex objects. Measurement: Journal of the International Measurement Confederation, 178.

Ozturk, H. R. (2020). A photogrammetry based method for determination of 3D morphological indices of coarse aggregates. Construction and Building Materials, 262.

Revilla-León, M., Rubenstein, J., Methani, M. M., Piedra-Cascón, W., Özcan, M., \& Att, W. (2021). Trueness and precision of complete-arch photogrammetry implant scanning assessed with a coordinate-measuring machine.

Stuani, Vitor. T., Ferreire, Rafael., Manfredi, Gustavo G.P., Cardoso, Matheus V., Sant'Ana, Adriana C.P. (2019). Photogrammetry as an alternative for acquiring digital dental models 